\title{
Article
}

\section{Functional foldamers that target bacterial membranes: the effect of charge, amphiphilicity and conformation}

Snape, Timothy James, Dennison, Sarah Rachel and Patil--sen, Yogita

Available at http://clok.uclan.ac.uk/14969/

Snape, Timothy James ORCID: 0000-0003-2766-4491, Dennison, Sarah Rachel ORCID: 0000-0003-4863-9607 and Patil--sen, Yogita ORCID: 0000-0002-42868874 (2016) Functional foldamers that target bacterial membranes: the effect of charge, amphiphilicity and conformation. Bioorganic \& Medicinal Chemistry, 24 (18). pp. 4241-4245. ISSN 0968-0896

It is advisable to refer to the publisher's version if you intend to cite from the work. http://dx.doi.org/10.1016/j.bmc.2016.07.017

For more information about UCLan's research in this area go to

http://www.uclan.ac.uk/researchgroups/ and search for <name of research Group>.

For information about Research generally at UCLan please go to http://www.uclan.ac.uk/research/

All outputs in CLoK are protected by Intellectual Property Rights law, including Copyright law. Copyright, IPR and Moral Rights for the works on this site are retained by the individual authors and/or other copyright owners. Terms and conditions for use of this material are defined in the policies page. 
Functional foldamers that target bacterial membranes: the effect of charge, amphiphilicity and conformation

School of Pharmacy and Biomedical Sciences, University of Central Lancashire, Preston, PR1 2HE, UK. Tel: +44 (0)1772 895805; E-mail: tjsnape@uclan.ac.uk.

Yogita Patil-Sen, Sarah R. Dennison and Timothy J. Snape*

Keywords: Foldamer; antibacterial; membrane; diarylureas; conformation

\begin{abstract}
By varying the molecular charge, shape and amphiphilicity of a series of conformationally distinct diarylureas it is possible to control the levels of phospholipid membrane lysis using membranes composed of bacterial lipid extracts. From the data obtained, it appears as though the lysis activity observed is not due to charge, conformation or amphiphilicity in isolation, but that surface aggregation, H-bonding and other factors may also play a part. The work provides evidence that this class of foldamer possesses potential for optimisation into new antibacterial agents.
\end{abstract}

\title{
Introduction
}

There can no longer be any doubt that new antibacterial agents are needed, drugs which not only have potent activity against resistant strains of bacteria, but which are less susceptible to developing resistance at a later date. The crisis associated with antimicrobial resistance has generated major world-wide opportunities for science and technology to lead the way, and one area that could deliver some of the answers is the field dedicated to foldamer research. ${ }^{1-5}$ A foldamer can be defined as "a discrete oligomer that folds into a conformationally ordered state in solution”, and contemporary research has shown that a number of foldamer constructs (in particular, antimicrobial peptides (AMPs)) can interact with, and disrupt, bacterial cell membranes thus making these agents valid candidates for future therapeutics, particularly if selectivity over host cells can be achieved. ${ }^{6-14}$

In light of this need, our research group has recently developed a range of AMP-influenced mimetics which are based on a foldamer scaffold, under the presumption that control over antimicrobial properties could be obtained by fine-tuning the molecules' charge, amphiphilicity and conformation. 8,10-13,15-19 Previous efforts have looked at the influence of 
foldamer length and conformation on membrane interaction, ${ }^{15-19}$ but as yet, the effects of charge and thereby amphiphilicity have not been studied against bacterial membranes by us. Herein, we outline recent efforts in this area and discuss the significance of these molecular properties on the ability of the compounds to lyse membranes composed of lipids extracted from Staphylococcus aureus (S. aureus) and Escherichia coli (E. coli), with the aim of developing a new class of antibacterial agent.

\section{Results and Discussion}

It is well established that $N$-unsubstituted diarylureas exhibit a distinct difference in conformation when compared to their fully $N$-substituted counterpart, both in solution and the solid state (Figure 1). For instance, upon full methylation, $N, N^{\prime}$-diphenylurea changes from the trans,trans-conformation to the cis,cis-conformation, as shown. ${ }^{20-23}$
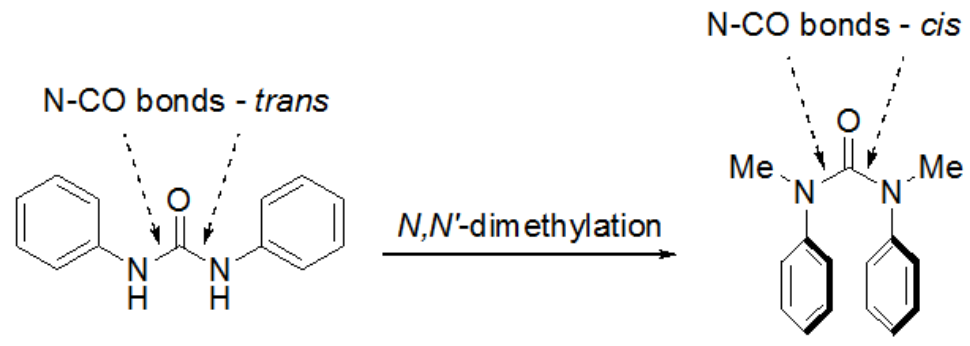

Figure 1: Conformational change induced in diphenylureas upon $N$-methylation.

In such a case the conformation can be determined by either ${ }^{1} \mathrm{H}$ NMR (solution state conformation), as evidenced by a diagnostic upfield shift in the aromatic signals, or by obtaining the X-ray crystal structures to determine the conformation in the solid state. ${ }^{24}$

The consequence of achieving such conformational control by simple $N$-substitution has been studied in a number of applications, not least: for facilitating conformational communication via stereogenic axes; ${ }^{25}$ for controlling oligourea helicity; ${ }^{26,27}$ for designing promising anticancer and anti-bacterial agents; ${ }^{15-17,28}$ as a molecular splint; ${ }^{29}$ for carrying out a so-called 'impossible’ macrocyclisation; ${ }^{30}$ and for the development of fluorescent sensors. ${ }^{31}$

Another way to potentially exploit this conformational switch is to prepare and evaluate compounds, which as a result, differ in their molecular dimensions and functionalities, such that activity can be studied and apportioned to the individual properties of interest in both the 
trans and cis forms, in this case their ability to lyse bacterial membranes; it is assumed that the pKa of the compounds being prepared, and thus their protonation state in the assay media, would be the same for both conformations.

In order to be able to test each property individually (conformation, charge and thereby amphiphilicity) a series of compounds were designed and prepared which exist in two discrete and stable conformations depending upon their $N$-methylation status, as outlined in Scheme 1 and Figure 2.

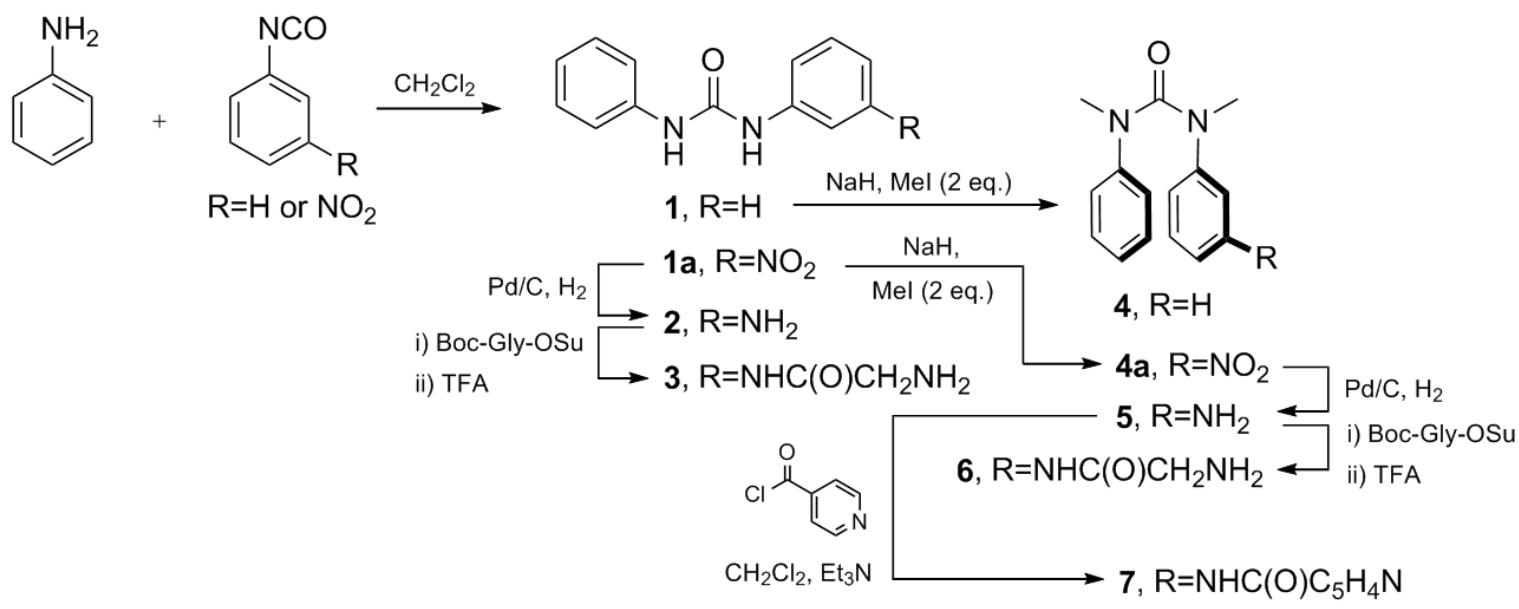

Scheme 1: Synthesis of the test compounds.

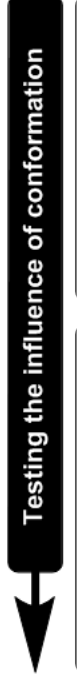

1-3 Testing the influence of charge at $\mathrm{pH} 7.4$

trans-trans-diarylureas

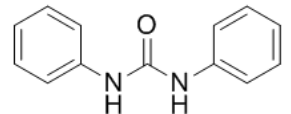

$1(0 \%)$

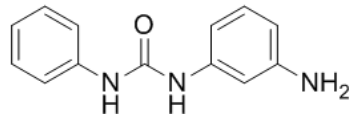

$2(0.16 \%)$

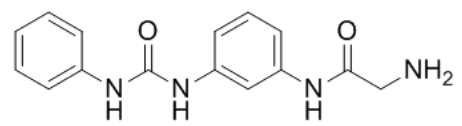

$3(99.9 \%)$

4-7 Testing the influence of charge at $\mathrm{pH} 7.4$
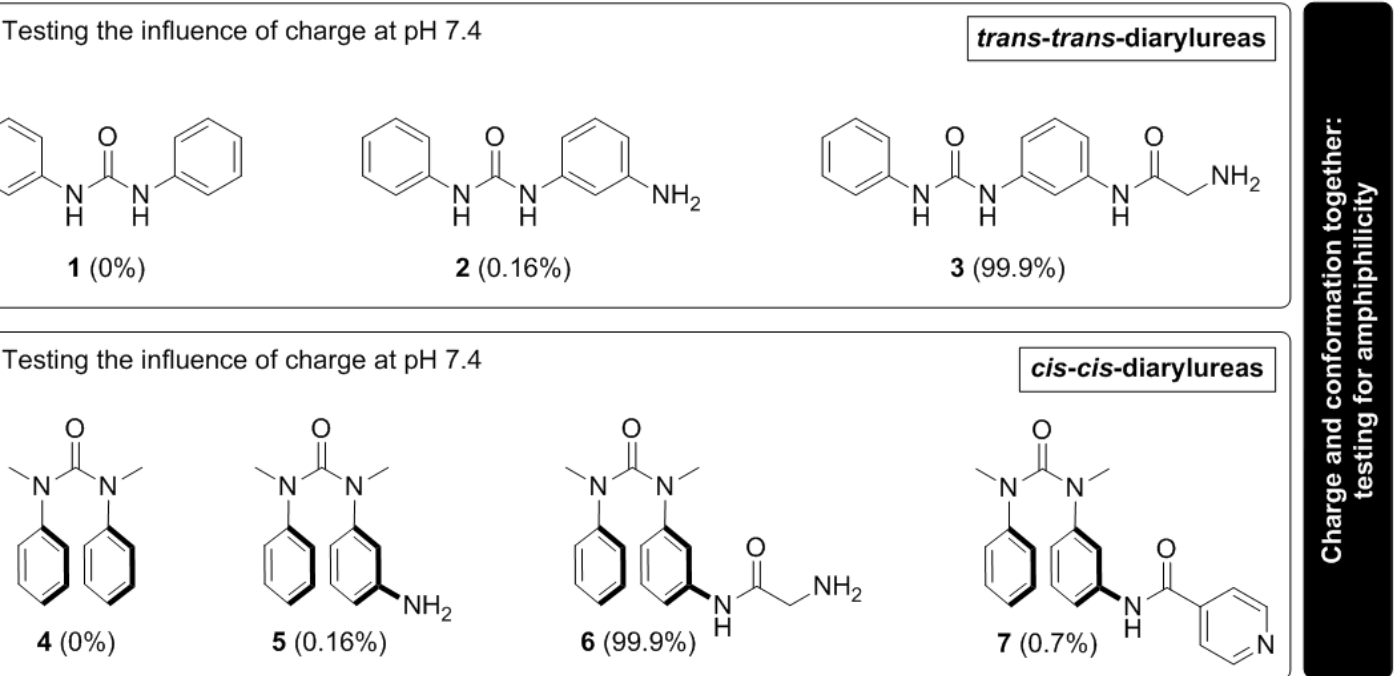
Figure 2: Compounds synthesised to test the influence of conformation, charge and amphiphilicity on membrane lysis. The percentages in parentheses are the approximate calculated values for protonation of the amine or pyridine nitrogen at pH 7.4 using the Henderson-Hasselbalch equation (see Supporting Information).

The compounds in Figure 2 were chosen to enable a direct comparison to be made between the level of membrane lysis achieved between compounds in the same conformation state, but differing protonation levels (series 1-3 and 4-7) vs. compounds in the same protonation state, but differing conformation ( 1 vs 4, 2 vs 5 and 3 vs 6). Compound 7 was a hybrid-type structure with both $\mathrm{N}-\mathrm{Me}$ and $\mathrm{N}-\mathrm{H}$ functionality and a protonation site.

Table 1: Percentage release for compounds 1-7 against calcein-loaded lipid vesicles prepared from the total

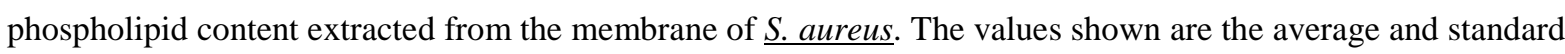
deviations of five experiments.

\begin{tabular}{|c|c|c|c|c|c|c|c|}
\hline Concentration $(\boldsymbol{\mu M})$ & $\mathbf{1}$ & $\mathbf{2}$ & $\mathbf{3}$ & $\mathbf{4}$ & $\mathbf{5}$ & $\mathbf{6}$ & $\mathbf{7}$ \\
\hline 0 & 0 & 0 & 0 & 0 & 0 & 0 & 0 \\
\hline 93.73 & $7.18 \pm 0.49$ & $4.58 \pm 0.27$ & $6.91 \pm 0.06$ & $2.59 \pm 1.03$ & $4.45 \pm 0.05$ & $4.45 \pm 2.49$ & $39.98 \pm 0.18$ \\
\hline 187.5 & $9.20 \pm 1.32$ & $8.34 \pm 0.19$ & $11.23 \pm 0.57$ & $5.71 \pm 0.13$ & $7.13 \pm 0.05$ & $10.00 \pm 0.18$ & $48.25 \pm 0.11$ \\
\hline 375 & $13.84 \pm 0.16$ & $10.09 \pm 0.25$ & $17.81 \pm 0.50$ & $12.79 \pm 0.28$ & $12.02 \pm 0.65$ & $11.80 \pm 0.37$ & $49.58 \pm 0.32$ \\
\hline 750 & $15.34 \pm 0.07$ & $12.67 \pm 0.41$ & $27.24 \pm 1.95$ & $14.16 \pm 0.41$ & $15.29 \pm 0.99$ & $13.21 \pm 0.20$ & $51.53 \pm 0.72$ \\
\hline 1500 & $18.34 \pm 0.23$ & $13.84 \pm 0.52$ & $31.25 \pm 0.40$ & $15.14 \pm 0.48$ & $21.23 \pm 0.53$ & $15.27 \pm 0.99$ & $53.10 \pm 1.07$ \\
\hline 3000 & $25.50 \pm 0.99$ & $15.47 \pm 0.30$ & $44.09 \pm 0.15$ & $24.10 \pm 0.35$ & $27.00 \pm 0.36$ & $17.84 \pm 0.60$ & $54.62 \pm 1.88$ \\
\hline
\end{tabular}

Table 2: Percentage release for compounds 1-7 against calcein-loaded lipid vesicles prepared from the total phospholipid content extracted from the membrane of $\underline{E \text {. coli }}$. The values shown are the average and standard deviations of five experiments.

\begin{tabular}{|c|c|c|c|c|c|c|c|}
\hline Concentration $(\boldsymbol{\mu M})$ & $\mathbf{1}$ & $\mathbf{2}$ & $\mathbf{3}$ & $\mathbf{4}$ & $\mathbf{5}$ & $\mathbf{6}$ & $\mathbf{7}$ \\
\hline 0 & 0 & 0 & 0 & 0 & 0 & 0 & 0 \\
\hline 93.73 & $3.17 \pm 0.26$ & $0.15 \pm 0.79$ & $1.10 \pm 2.23$ & $0.82 \pm 0.62$ & $2.30 \pm 0.31$ & $8.45 \pm 1.23$ & $24.05 \pm 0.16$ \\
\hline 187.5 & $6.27 \pm 3.19$ & $0.95 \pm 0.58$ & $6.06 \pm 0.68$ & $2.05 \pm 0.65$ & $5.72 \pm 0.20$ & $27.22 \pm 2.42$ & $24.81 \pm 0.05$ \\
\hline 375 & $6.47 \pm 1.46$ & $1.24 \pm 0.69$ & $9.17 \pm 2.04$ & $4.25 \pm 1.35$ & $6.75 \pm 0.40$ & $29.32 \pm 0.17$ & $26.28 \pm 0.62$ \\
\hline 750 & $8.53 \pm 0.22$ & $1.73 \pm 0.56$ & $16.63 \pm 4.19$ & $6.44 \pm 1.96$ & $7.44 \pm 0.62$ & $29.98 \pm 0.32$ & $29.08 \pm 2.60$ \\
\hline 1500 & $12.02 \pm 0.14$ & $1.78 \pm 0.47$ & $23.46 \pm 3.42$ & $7.28 \pm 0.87$ & $8.03 \pm 0.43$ & $30.97 \pm 0.42$ & $33.61 \pm 0.12$ \\
\hline 3000 & $14.85 \pm 1.73$ & $2.17 \pm 0.70$ & $29.17 \pm 0.53$ & $9.02 \pm 0.65$ & $9.65 \pm 0.30$ & $35.55 \pm 1.12$ & $35.31 \pm 0.09$ \\
\hline
\end{tabular}

Tables 1 and 2 show the concentration-dependent lysis of compounds 1-7 against membrane extracts from S. aureus and E.coli respectively, over a treatment period of $1 \mathrm{~h}$, in a calceinrelease assay. The relatively weak maximum levels of lysis obtained, even at the highest concentrations, suggests that the compound-membrane interactions are not optimised against 
the membranes being studied. These results were confirmed in minimum inhibitory concentration (MIC) studies against cultures of both bacterial strains (Table 3), whereby relatively high values were observed. However, it should be noted that these are small, individual monomer molecules interacting with relatively large phospholipid membranes which are usually disrupted by large aggregated oligomers. Herein attempts have been made to identify key features for membrane interaction and disruption which will be taken forward into larger oligomers in future work.

Nonetheless, modest levels of membrane lysis are observed at the lowest concentration studied (Tables 1 and 2), where the highest levels are given by 7 ( 40\%) against $S$. aureus and 7 ( 24\%) against E. coli. Importantly, the variety of lysis levels obtained against both strains is indicative of some selectivity being observed with the different compounds, which differ in their charge, shape and amphiphilicity, against theses membranes, suggesting that once optimised, this class of molecule could be developed as pathogen-selective antimicrobial agents.

Table 3: Minimum inhibitory concentration (MIC) studies against both S. aureus and E. coli cultures.

\begin{tabular}{|c|c|c|c|c|c|c|c|}
\hline Bacteria & $\mathbf{1}$ & $\mathbf{2}$ & $\mathbf{3}$ & $\mathbf{4}$ & $\mathbf{5}$ & $\mathbf{6}$ & $\mathbf{7}$ \\
\hline S. aureus & $2.0 \mathrm{mM}$ & $2.5 \mathrm{mM}$ & $1.5 \mathrm{mM}$ & $2.5 \mathrm{mM}$ & $2.0 \mathrm{mM}$ & $2.5 \mathrm{mM}$ & $1.0 \mathrm{mM}$ \\
\hline E. coli & $>3.0 \mathrm{mM}$ & $>3.0 \mathrm{mM}$ & $2.0 \mathrm{mM}$ & $>3.0 \mathrm{mM}$ & $>3.0 \mathrm{mM}$ & $2.0 \mathrm{mM}$ & $2.0 \mathrm{mM}$ \\
\hline
\end{tabular}

\section{Comparisons: Structure and lysis}

Against $S$. aureus the trans,trans-compounds 1, 2 and $\mathbf{3}$ are more membrane lytic than the cis,cis-isomers 4, 5 and $\mathbf{6}$ at almost all concentrations studied, with $\mathbf{3}$ being the most potent compound overall. Presumably, this is the case because this amine is the most ionised at the $\mathrm{pH}$ used (pH 7.4, Figure 2), but that conformation or H-bonding must play a role too, since these are the main structural differences between compounds $\mathbf{3}$ and the less active analogue, 6. That said, compound 7, a cis,cis-diarylurea-NH-amide, which is less completely protonated at $\mathrm{pH} 7.4$, is better still by several fold than all the trans,trans-compounds suggesting that more complicated factors are at play.

Interestingly, in the context of pathogen-selectivity, against $E$. coli the pattern is different, with 1 being the best of the trans,trans-analogues (despite being neutral at $\mathrm{pH}$ 7.4), although the overall levels of lysis are slightly lower than the same compounds against $S$. aureus. Conversely, in all cases, the cis,cis-compounds (5 and $\mathbf{6}$ ) tend to be more active than the 
trans,trans-compounds ( 2 and 3), with compound $\mathbf{6}$ being the best diarylurea overall by several fold, and comparable to compound 7.

From the data in Tables 1 and 2 it appears as though lysis does correlate with the pKa of the nitrogen which is protonated for compounds 1-6, such that the glycine derivatives $\mathbf{3}$ and $\mathbf{6}$ (99.9\% positively charged) are consistently the best lytic compounds against both membrane types. The membrane of $S$. aureus is mainly composed of the negatively charged dimyristoylphosphatidylglycerol (DMPG) lipid, whilst the membrane of E. coli is mainly the negatively charged DMPG and the zwitterionic (neutral) dimyristoylphosphatidylethanolamine (DMPE) lipid. ${ }^{32}$ As such, with the membrane's overall negative charge, it is expected that the positively charged compounds $\mathbf{3}$ and $\mathbf{6}$ would be the best at interacting with the membranes and ultimately lysing them at a critical concentration (albeit relatively high with these low molecular weight, un-optimised compounds). In addition, hydrophobic features to penetrate the lipid layer of the membrane are important confirming that amphiphilic molecules as a whole are required. ${ }^{8}$

Interestingly, compound $\mathbf{4}$ is poor against both strains of bacteria, as would be expected for a neutral, weakly amphiphilic compound with no H-bond donor capability, but $\mathbf{1}$ sits right in the middle of $\mathbf{2}$ and $\mathbf{3}$ in terms of is lytic ability against both E. coli and S. aureus. Presumably, this is due, in-part at least, to its capacity to H-bond both to itself and aggregate at the membrane surface, thus disrupting the membranes' electrical balance, and subsequently inducing leakage of cytoplasmic material leading to cell rupture, whereas $\mathbf{4}$ is unable to do so.

\section{Membrane permeabilisation}

To confirm that the compounds are acting through a membrane disruptive mechanism, as a consequence of membrane insertion, rather than through endocytosis, a membrane permeabilisation assay was conducted using $1-N$-phenylnaphthylamine (NPN) as the fluorometric probe. ${ }^{33}$ NPN fluoresces strongly in phospholipid environments but only weakly in aqueous environments, and intact outer membranes of bacteria are able to exclude this external hydrophobic probe, forcing it to remain in the aqueous environment. However, in the presence of certain membrane-permeabilising agents, the membrane becomes compromised and thus sensitive to external factors. As a consequence, this sensitisation allows entry of the hydrophobic probe into the hydrophobic environment of the membrane. Thus, by virtue of its 
fluorescence in hydrophobic environments, measuring NPN uptake gives an indication of any changes to the permeability of the outer membrane.

Table 4: Percentage uptake of NPN by S. aureus and E. coli in the presence of the test compounds at $2 \mathrm{mM}$.

\begin{tabular}{|c|c|c|c|c|c|c|c|c|}
\hline \multirow{2}{*}{ Time } & Bacteria & $\mathbf{1}$ & $\mathbf{2}$ & $\mathbf{3}$ & $\mathbf{4}$ & $\mathbf{5}$ & $\mathbf{6}$ & $\mathbf{7}$ \\
\hline \multirow{2}{*}{$1 \mathrm{hr}$} & S. aureus & $46.01 \pm 5.57$ & $38.91 \pm 3.20$ & $69.56 \pm 7.31$ & $43.82 \pm 5.79$ & $46.26 \pm 4.81$ & $40.60 \pm 5.49$ & $50.59 \pm 1.31$ \\
\cline { 2 - 9 } & E. coli & $45.29 \pm 4.49$ & $33.93 \pm 3.21$ & $47.09 \pm 3.95$ & $40.75 \pm 1.88$ & $40.18 \pm 2.83$ & $42.47 \pm 5.51$ & $49.57 \pm 1.55$ \\
\hline \hline \multirow{2}{*}{ Overnight } & S. aureus & $49.40 \pm 4.82$ & $19.29 \pm 5.60$ & $69.56 \pm 9.02$ & $44.34 \pm 3.02$ & $53.57 \pm 7.47$ & $36.81 \pm 5.03$ & $57.33 \pm 5.05$ \\
\cline { 2 - 9 } & E. coli & $30.02 \pm 7.76$ & $16.34 \pm 4.30$ & $50.93 \pm 4.70$ & $38.67 \pm 5.20$ & $48.79 \pm 11.32$ & $52.87 \pm 9.19$ & $52.34 \pm 5.39$ \\
\hline
\end{tabular}

For the purposes of proof-of-concept, the membrane-permeabilising NPN assay was performed at the MIC concentration ( $2 \mathrm{mM})$, since this is the concentration at which the dosedependent curves begin to plateau and would represent the maximum levels of insertion.

Table 4 shows the percent lysis compared to polymyxin B, an established membranepermeable antibacterial peptide, as control. ${ }^{34}$ Although uptake of NPN into the membrane is moderate in the presence of the test compounds (up to 70\%, Table 4), compared to polymyxin B as control, the MIC activity is overall weak. Nevertheless, the fact that membrane insertion is confirmed suggests that potential exists to optimise the lytic properties of this compound class, especially if oligomeric constructs can be developed to increase the effective concentration of the amphiphilic monomers exposed to the membrane.

\section{Integy moment}

The change in shape associated with $N, N$ '-dimethylation of diarylureas (Figure 1 ) causes aromatic stacking to occur such that the net molecular dimensions are reduced and thus the distance between the centre of the lipophilic aromatic sections and the hydrophilic charge is reduced in the cis,cis-diarylureas compared to the trans,trans. As a result, the more folded cis,cis-conformers would have different integy moments (the integy moment is a measure of amphiphilicity which expresses the unbalance between the centre of mass of a molecule and the barycenter of its hydrophilic or hydrophobic regions) ${ }^{35}$ compared to the extended trans,trans-conformers, thereby providing a physical property for which to correlate against any observed membrane lysis. Unfortunately, attempts to correlate the levels of lysis of $S$. aureus and E. coli membranes with the integy moments (IW) of the test compounds, did not yield any noticeable trends, despite precedent of such a correlation being known with synthetic peptide mimics, ${ }^{8}$ suggesting that the lysis activity observed is not due to charge, conformation or amphiphilicity in isolation, but that surface aggregation, H-bonding and 
other factors may also play a part. Although in isolation the change in conformation must affect the integy moment of compounds 1-3 vs. 4-7, presumably the removal of two hydrogen-bond donors $(\mathrm{N}-\mathrm{H})$ upon $N$-methylation to give series 4-7, changes the integy moments and complicates any correlation, as does the difference in protonation states of the nitrogen atoms under the physiologically relevant $\mathrm{pH}$ of 7.4 used.

\section{Conclusion}

We have shown that by varying the molecular charge, shape, and thus amphiphilicity, of a series of diarylureas, it is possible to control the level of lysis of membranes composed of bacterial lipid extracts. The molecular structures have not been optimised and thus future work will set out to combine the best features required for membrane lysis (high pKa amine(s) or permanent positive charge(s) and lipophilic group(s), sufficiently separated along the molecular axis giving rise to significant integy moments) into new compounds and begin to extend the structures to oligomeric scaffolds in the hope of designing new antibacterial agents. From the data obtained so far, it appears as though the lysis activity observed is not due to charge or amphiphilicity in isolation, but that surface aggregation, H-bonding and other factors may also be at play, nevertheless, that membrane permeability takes place has been proven in the NPN assay.

\section{Acknowledgements}

The authors would like to thank the EPSRC UK National Mass Spectrometry Facility at Swansea University for acquiring the accurate mass data, and the University of Central Lancashire for support.

\section{References}

(1) Gellman, S. H. Accounts of Chemical Research 1998, 31, 173.

(2) Guichard, G.; Huc, I. Chem. Commun. 2011, 47, 5933.

(3) Huc, I. European Journal of Organic Chemistry 2004, 17.

(4) J.Hill, D.; M. J. Mio; R. B. Prince; T. S. Hughes; Moore, J. S. Chemical Reviews 2001, 101, 3893.

(5) Saraogi, I.; Hamilton, A. D. Chemical Society Reviews 2009, 38, 1726.

(6) B. Bechinger; Lohner, K. Biochimica et biophysica acta 2006, 1758, 1529.

(7) Dennison, S. R.; Wallace, J.; Harris, F.; Phoenix, D. A. Protein and Peptide Letters 2005, 12, 31.

(8) H. D. Thaker; A. Cankaya; R. W. Scott; Tew, G. N. Acs Medicinal Chemistry Letters 2013, 4, 481.

(9) Strömstedt, A. A.; Ringstad, L.; Schmidtchen, A.; Malmsten, M. Current Opinion in Colloid \&amp; Interface Science 2010, 15, 467. 
(10) G. J. Gabriel; Tew, G. N. Org. Biomol. Chem. 2008, 6, 417.

(11) Som, A.; Vemparala, S.; Ivanov, I.; Tew, G. N. Biopolymers 2008, 90, 83.

(12) Tew, G. N.; Scott, R. W.; Klein, M. L.; Degrado, W. F. Accounts of Chemical Research 2010, 43, 30.

(13) Choi, S.; Isaacs, A.; Clements, D.; Liu, D.; Kim, H.; Scott, R. W.; Winkler, J. D.; DeGrado, W. F. Proceedings of the National Academy of Sciences of the United States of America 2009, 106, 6968.

(14) Czaplewski, L.; Bax, R.; Clokie, M.; Dawson, M.; Fairhead, H.; Fischetti, V. A.; Foster, S.; Gilmore, B. F.; Hancock, R. E. W.; Harper, D.; Henderson, I. R.; Hilpert, K.; Jones, B. V.; Kadioglu, A.; Knowles, D.; Olafsdottir, S.; Payne, D.; Projan, S.; Shaunak, S.; Silverman, J.; Thomas, C. M.; Trust, T. J.; Warn, P.; Rex, J. H. Lancet Infectious Diseases 2016, 16, 239.

(15) Dennison, S. R.; Akbar, Z.; Phoenix, D. A.; Snape, T. J. Soft Matter 2012, 8, 3258.

(16) Dennison, S. R.; Phoenix, D. A.; Snape, T. J. Bioorg Med Chem Lett 2013, 23, 2518.

(17) Dennison, S. R.; Snape, T. J.; Phoenix, D. A. European Biophysics Journal with Biophysics Letters 2012, 41, 687.

(18) S. Fahs; F. B. Rowther; S. R. Dennison; Y. Patil-Sen; T. Warr; Snape, T. J. Bioorg Med Chem Lett 2014, 24, 3430.

(19) Hester, T. J.; Dennison, S. R.; Baker, M. J.; Snape, T. J. Org. Biomol. Chem. 2015, 13, 8067.

(20) Lepore, G.; Migdal, S.; Blagdon, D. E.; Goodman, M. J. Org. Chem. 1973, 38, 2590.

(21) Lepore, U.; Lepore, G. C.; Ganis, P.; Germain, G.; Goodman, M. J. Org. Chem. 1976, 41, 2134.

(22) Kagechika, H.; Azumaya, I.; Tanatani, A.; Fukutomi, R.; Yamaguchi, K.; Shudo, K. Abstracts of Papers of the American Chemical Society 1998, 216, U494.

(23) Tanatani, A.; Kagechika, H.; Azumaya, I.; Fukutomi, R.; Ito, Y.; Yamaguchi, K.; Shudo, K. Tetrahedron Lett. 1997, 38, 4425.

(24) Itai, A.; Toriumi, Y.; Saito, S.; Kagechika, H.; Shudo, K. J. Am. Chem. Soc. 1992, $114,10649$.

(25) Clayden, J.; Vallverdu, L.; Helliwell, M. Org. Biomol. Chem. 2006, 4, 2106.

(26) Kudo, M.; Hanashima, T.; Muranaka, A.; Sato, H.; Uchiyama, M.; Azumaya, I.; Hirano, T.; Kagechika, H.; Tanatani, A. J. Org. Chem. 2009, 74, 8154.

(27) Clayden, J.; Lemiegre, L.; Morris, G. A.; Pickworth, M.; Snape, T. J.; Jones, L. H. J. Am. Chem. Soc. 2008, 130, 15193.

(28) Snape, T. J.; Karakoula, K.; Rowther, F.; Warr, T. Rsc Advances 2012, 2, 7557.

(29) Yamaguchi, K.; Matsumura, G.; Kagechika, H.; Azumaya, I.; Ito, Y.; Itai, A.; Shudo, K. J. Am. Chem. Soc. 1991, 113, 5474.

(30) Campbell, F.; Wilson, A. J. Tetrahedron Lett. 2009, 50, 2236.

(31) Hirano, T.; Osaki, T.; Fujii, S.; Komatsu, D.; Azumaya, I.; Tanatani, A.; Kagechika, H. Tetrahedron Lett. 2009, 50, 488.

(32) Lohner, K.; Prenner, E. J. Biochim. Biophys. Acta 1999, 1462, 141.

(33) Helander, I. M.; Mattila-Sandholm, T. Journal of Applied Microbiology 2000, 88, 213.

(34) Falagas, M. E.; Rafailidis, P. I.; Matthaiou, D. K. Drug Resistance Updates 2010, 13, 132.

(35) http://www.moldiscovery.com/software/vsplus/ 